\title{
Evaluation of Foot Deformity Using a Three-Dimensional Geometric Model
}

\author{
J.P. Sirois. ${ }^{1}$, P. Allard ${ }^{2,3}$, M. Duhaime ${ }^{3,4}$, G. Geoffroy ${ }^{2,5}$ and J. Kofman ${ }^{3}$
}

\begin{abstract}
A three-dimensional geometric model of the foot's bony structure based on the use of a stereoradiographic technique is presented. To illustrate the potential of such a model it has been applied here to the study of cavus foot in a patient having Friedreich's ataxia. This model permits an accurate evaluation of this complex spatial foot deformity.
\end{abstract}

RÉSUMÉ: Une modèlisation de la structure osseuse du pied utilisant une technique radiologique biplanaire et un algorithme photogrammétrique sont présentés. Afin d'illustrer le potentiel d'un tel modèle, il a été appliqué à l'étude du pied creux d'un patient atteint d'ataxie de Friedreich. Ce modèle permet une évaluation précise des déformités complexes du pied.

Can. J. Neurol. Sci. 1984; 11:578-581

The study of the foot's bony structure with conventional radiographic techniques poses certain difficulties. This is due to the number of bones in the foot, to their irregular shape, to the state of weight or non-weight bearing as well as to the radiographic technique used. It follows that in radiographic studies the foot tends to be viewed as a planar structure rather than as a three-dimensional object (Gamble and Yale, 1975).

In order to quantitatively and accurately evaluate foot deformities a three-dimensional model of the foot needs to be developed. The model of the foot's bony structure proposed is essentially a schematization in three-dimensional space of the bones of the tarsus, metatarsus, phalanges, and of the tibia and fibula. One thus obtains a known arrangement of simple geometric shapes that reflect the essential structural characteristics of the foot. As such, modeling of the foot is divided into three distinct stages, the production of standardized X-rays, the digitilization of bony landmarks on these X-rays and finally obtaining the three-dimensional position of the digitized bony landmarks. Afterwards, the specific structural parameters associated with the deformity can be defined either in three or two dimensions.

\section{X-Ray Standardization}

Several factors affect the radiographic image of the foot. The position of the foot with respect to the support plane, the film cassette and the X-ray source are the most critical. To use radiographic images of the foot as an input to a geometric model, these factors must be controlled. The apparatus illustrated in Fig. 1 had been especially designed to fulfill this purpose (Sibille et al. 1982). Repeatable standardized X-rays are produced by placing the feet in a fifteen degree plantar flexed attitude and simulating weight-bearing by the application of a force to the flexed knees. The apparatus thus permits identical X-raying techniques for ambulant and non-ambulant patients. Small steel spherical markers embedded into the plexiglass frame are used to calibrate the X-rays. This is essential for subsequent photogrammetric transformations.

The use of the standardizing apparatus in a clinical setting poses no particular problems. In short, the patient lying on his back rest his feet on the platform; then a calibrated force approximating body weight is applied on his flexed knees by means of power screw and calibrated compression spring. Different $\mathrm{X}$-ray views can be produced by placing a film cassette beneath the platform on which the feet lie and shifting the overhead X-ray source, taking care that the calibration markers be included in each exposure. The choice of the best pair of $\mathrm{X}$-ray views is a compromise between adequate image divergence required for photogrammetric transformations and clear imaging of all the bones of the foot. The first X-ray chosen is the anterior-posterior view, while the second is a fifteen degree oblique view obtained by laterally shifting the X-ray source.

\section{Data Acquisition}

The second step in the process is transferring information from the X-rays to a numerical form compatible with the geometric

From the Department of Physical Education, University of Montreal (1), the Paediatric Research Centre, Sainte-Justine Hospital, Montreal (2), the School of Physical and Occupational Therapy, McGill University (3). the Service of Orthopaedic Surgery (4), and the Department of Neurology, Sainte-Justine Hospital, Montreal (5).

Reprint requests for the complete supplement (Phase 3, Part 3) to: Prof. André Barbeau. Clinical Research Institute of Montreal. 110 Pine Avenue West. Montreal. Quebec. Canada. H2W IR7. 


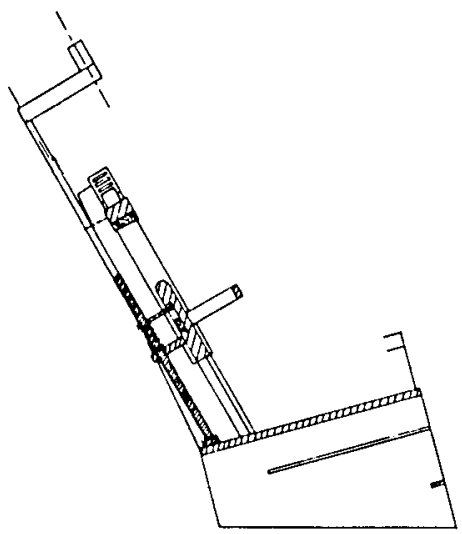

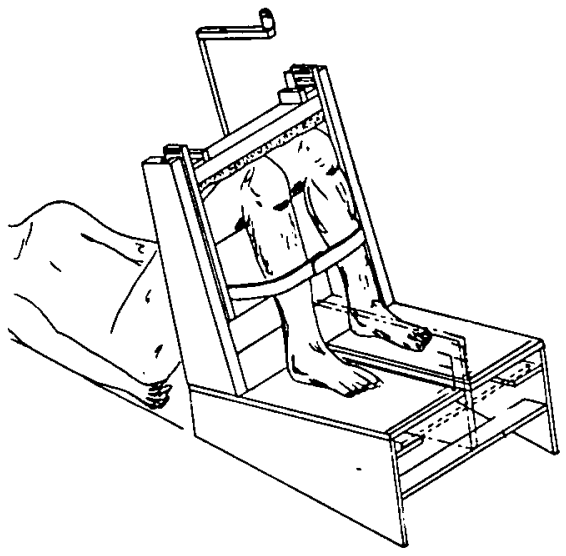

Figure 1-Apparatussimulating weight-bearing effects to standardized foot radiographs. model. Essentially, this consists of obtaining the image coordinates from both X-ray views. In practice the radiographs are laid on a transluscent digitizing table where image coordinates are obtained by identifying them by means of a magnetic stylus. First, images of the calibration markers are located followed by the anatomical images of interest. One must realize that recognizing the image of the same anatomical structure in two diverging $X$-rays is not always straight-f orward. Some bony structures present smooth curves on which a specific anatomical landmark is difficult to identify; for this reason two approximation techniques are used. In the case of bony margins that can be delineated, the midpoint of the path is taken as the image of a distinct anatomical point. In the case where only an area of the bone can be outlined, the centroid of the area is taken as the image of a distinct anatomical point. These numerical techniques are illustrated in Fig. 2 A) and 2 B) respectively. In Fig. 3 an overview of the bony landmarks digitized in both $\mathrm{X}$-rays is presented. It is noticed that on the bones of the tarsus three points are identified while for the metatarsus and phalanges only two points are used.

\section{Data Reduction}

Obtaining the three-dimensional position of identified bony landmarks is the final step in the modelization process. Though there exist many different approaches to the spatial resection problem, be they analytical or numeric as proposed by Brown et al., (1976) and Aziz et al. (1971) respectively, they all provide as an output the precise spatial position of the imaged object. Presently the algorithm proposed by Brown et al. (1976) is used, for it is simple and reasonably accurate. These operations are carried out on the University of Montreal's Cyber 855 central computer.

\section{Three-Dimensional Model}

As previously stated, this model of the foot's bony structure describes the position and orientation of various bones, as schematized in Fig. 4. Bones on which three points have been identified are represented by a triangle while bones on which only two points were identified are represented by a line segment. These particularities stem from the complexity of the bones' shape as well as their typical articular movement. The three



A

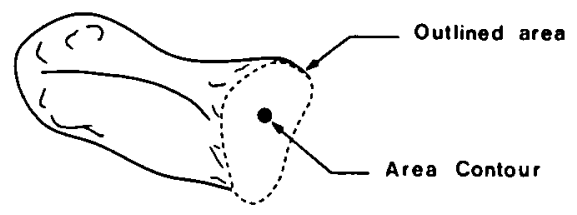

B

Figure 2 - Illustration of $(A)$ the mid-point and $(B)$ of the centroid techniques.

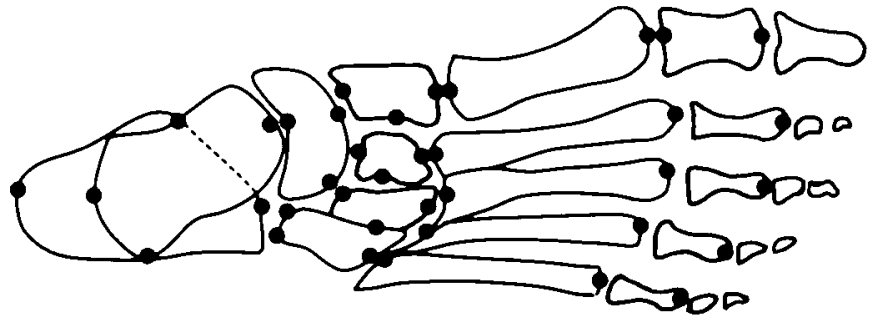

Figure 3 - Bony landmarks utilized to uniquely identify the foot's intricate geometry. 


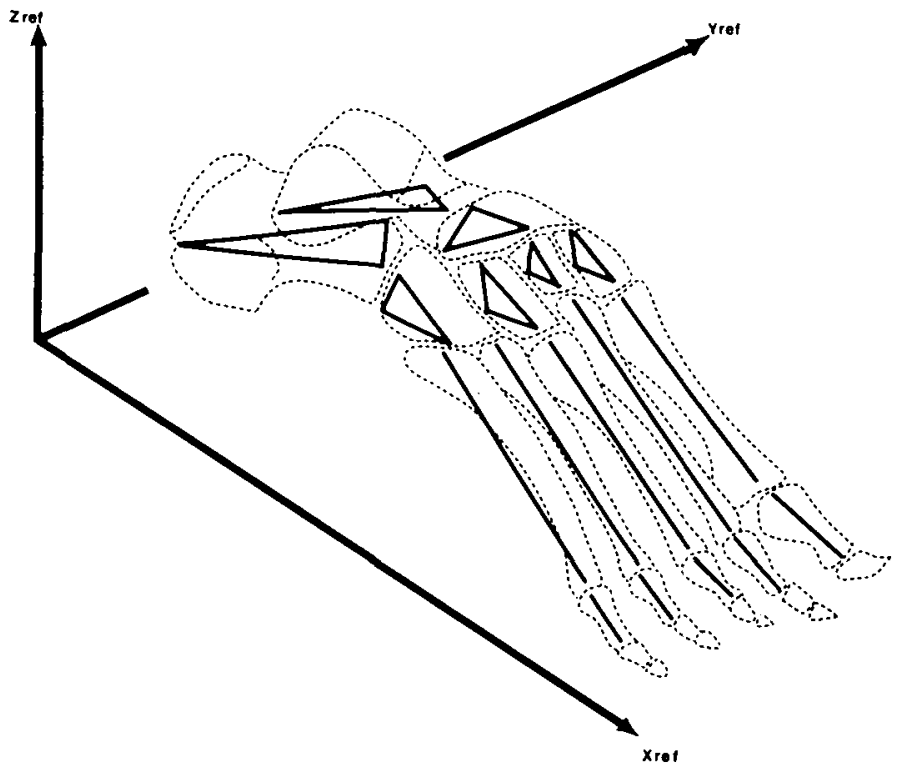

Figure 4 - Schematic spatial representation of the foot as computed from a bi-planar radiographic technique.

point representation completely describes the orientation of a bone whereas the two point representaion leaves a possible rotation about the defined line segment undetected. The metatarsals and phalanges are modeled by a line segment drawn between the mid-points of their anterior and posterior articulations. The bones of the mid-tarsus and of the hindfoot are modeled by three line segments originating on their anterior, posterior and lateral facets. The ankle joint, through not strictly a bony structure of the foot, is modeled by the line segment drawn between the lower extremities of the malleoli.

\section{Indices for Evaluating Foot Structure}

Spatial position of specified anatomical landmarks do not directly indicate foot deformity, nor do geometrical representations such as line segments and triangles. However, the threedimensional model proposed does enable one to define a considerable number of geometrical parameters such as the spatial angle between two bones, the distance between mating articular surfaces and the orientation of a bone with respect to the support plane. In order to better apprehend the capabilities of the model, it was first validated then applied in a limited fashion to a cavus foot deformity of a patient having Friedreich's ataxia.

\section{Validation}

To verify the reconstruction technique, three pairs of stereoradiographs of a skeletal foot were taken. Mean values were used to calculate six parameters which were compared with those obtained by direct measurements. These values and two others are presented in Table $I$.

The mean difference between the measured and calculated tri-dimensional values are approximately $5 \mathrm{~mm}$. A comparison of the measured values with the corresponding bi-dimensional values gives a mean difference of approximately $7 \mathrm{~mm}$. The difference between this value and that obtained using the proposed
Table 1: Tri-Dimensional and Bi-Dimensional Parameters of the Skeletal Foot

\begin{tabular}{|c|c|c|c|c|c|}
\hline $\begin{array}{c}\text { Three- } \\
\text { Dimensional } \\
\text { Parameters }\end{array}$ & $\begin{array}{c}\text { Measured } \\
\text { 3-D Values }\end{array}$ & $\begin{array}{l}\text { Calculated } \\
\text { 3-D Values }\end{array}$ & $\begin{array}{l}\text { Projected } \\
\text { 3-D Values }\end{array}$ & $\begin{array}{l}\text { Calculated } \\
\text { 2-D Values }\end{array}$ & $\begin{array}{l}\text { Two- } \\
\text { Dimensional } \\
\text { Parameters }\end{array}$ \\
\hline $\begin{array}{l}\text { Length (mm) of } \\
\text { the longitudinal } \\
\text { axis of: }\end{array}$ & & & & & $\begin{array}{l}\text { Length }(\mathrm{mm}) \text { in } \\
\text { the DP view of: }\end{array}$ \\
\hline metatarsal I & 56 & 64 & 49 & 54 & metatarsal I \\
\hline metatarsal 2 & 66 & 65 & 58 & 56 & metatarsal 2 \\
\hline metatarsal 3 & 73 & 62 & 53 & 56 & metatarsal 3 \\
\hline metatarsal 4 & 59 & 55 & 50 & 56 & metatarsal 4 \\
\hline metatarsal 5 & 60 & 55 & 52 & 56 & metatarsal 5 \\
\hline $\begin{array}{l}\text { Width }(\mathrm{mm}) \text { of } \\
\text { the forefoot }\end{array}$ & 69 & 67 & 65 & 63 & $\begin{array}{l}\text { Width (mm) of } \\
\text { the forefoot } \\
\text { (DP view) }\end{array}$ \\
\hline $\begin{array}{l}\text { I-V metatarsal } \\
\text { angle }\end{array}$ & & $33^{\circ}$ & $20^{\circ}$ & $25^{\circ}$ & $\begin{array}{l}\text { I-V metatarsal } \\
\text { angle } \\
\text { (DP view) }\end{array}$ \\
\hline $\begin{array}{l}\text { Angle of } \\
\text { metatarsal } \\
\text { torsion }\end{array}$ & & $26^{\circ}$ & & & $\begin{array}{l}\text { Corresponding } \\
\text { angle not } \\
\text { available }\end{array}$ \\
\hline
\end{tabular}

technique is $2 \mathrm{~mm}$ for length measurements of bones located in a plane parallel to that of the radiograph. One assumes that a greater variation will be encountered for angle measurement and lengths of bones spatially oriented. The mean variation between the bidimensional values and their corresponding projected tri-dimensional values in the $\mathrm{X}-\mathrm{Y}$ plane is approximately $3 \mathrm{~mm}$ for length and $4^{\circ}$ for the angle measured.

In addition to the conventional measurements the tridimensional values allow development of parameters not available with the conventional planar radiographs due to bony superimposition. For example, the angle of metatarsal torsion, which is the angle subtended by the lines joining the I and V metatarsal heads and bases respectively is $26^{\circ}$.

\section{Clinical Results}

Three bony structures of greatest interest in pes cavus are the calcaneus, the talus and the metatarsals. In particular three structural indices are calculated, the spatial angle between the longitudinal shafts of the first and fifth metatarsals, the spatial angle between the first metatarsal and the calcaneus and finally the spatial angle between the talus and the calcaneus. The values as well as the clinical interpretation of the indices are indicated in Table 2. Clinical norms for these three-dimensional

Table 2: Results obtained from a cavus for deformity and a skeleton foot

\begin{tabular}{|c|c|c|c|c|c|}
\hline $\begin{array}{c}\text { Spatial } \\
\text { Angle }\end{array}$ & $\begin{array}{l}\text { Normal } \\
\text { Values* }\end{array}$ & Cavus Foot & $\begin{array}{c}\text { Foot } \\
\text { Skeleton }\end{array}$ & $\begin{array}{c}\text { Relative } \\
\text { Difference } \\
\text { Between } \\
\text { CF and SF }\end{array}$ & Interpretation \\
\hline & (degree) & $\underset{\text { (degree) }}{\mathbf{C F}}$ & $\begin{array}{c}\text { FS } \\
\text { (degree) }\end{array}$ & (degree) & \\
\hline $\begin{array}{l}\text { Ist }-5 \text { th } \\
\text { metatarsals }\end{array}$ & $N / A$ & 51 & 26 & 25 & $\begin{array}{l}\text { forefoot } \\
\text { pronaton }\end{array}$ \\
\hline $\begin{array}{l}\text { Ist-meta.: } \\
\text { calcaneus }\end{array}$ & 147 & 95 & 121 & -26 & $\begin{array}{l}\text { arch elevation } \\
\text { and forefoot } \\
\text { inversion }\end{array}$ \\
\hline $\begin{array}{l}\text { talus- } \\
\text { calcaneus }\end{array}$ & 30 & 54 & 40 & 14 & $\begin{array}{l}\text { calcaneal } \\
\text { rotation }\end{array}$ \\
\hline
\end{tabular}


indices do not exist, thus these preliminary results were initially compared with those obtained from a foot skeleton. Though the significance of this comparison is limited, it does agree in essence with results from a more exhaustive study on cavus foot deformity in Friedreich's ataxia (Allard et al., 1982) where cavus foot is described by a heightening of the medial arch, forefoot pronation and varus of the calcaneus.

\section{CONClusion}

A three-dimensional model of the foot structure was presented and applied to the cavus foot. However it is not limited to the study of a particular foot deformity. Rather, the choice of bony structure studied and the spatial parameters defined make it a very versatile technique. It is hoped that in the future a data bank of normal foot structure be established.

\section{ACKNOWLEDGEMENT}

This work was funded by l'Association Canadienne de l'Ataxie de Friedreich.

\section{REFERENCES}

Abdel-Aziz Yi, Karara HM (1971) Direct Linear Transformation from Comparative Coordinates Into Object Space Coordinated in CloseRange Photogrammetry. Proceedings ASP/VI, Symposium on Close Range Photogrammetry, 1-18.

Allard P, Sirois JP. Thiry PS, Geoffroy G, Duhaime M (1982) Roentnographic Study of Cavus Foot Deformity in Friedreich Ataxia Patients: Preliminary Report. Can J Neur Sc 9. 113-118.

Brown RH, Burnstein AH, Nash CL, Schock CC (1976) Spinal Analysis Using a Three-Dimensional Radiographic Technique. J Biomech 9. 355-365

Gamble RO, Yale I (1975) Clinical foot Roentgenology. RE Kreiger. Sibille J, Tremblay C, Thiry PS, Allard P (1982) Apparatus for Normalized Bi-Planar Radiographs of the Foot. Journal of Biomechanics. 15 page 34.

Steel MW III, Johnson KA, Deevitz MA, Illstrup DM (1980) Radiographic Measurements of the Normal Adult Foot. Foot and Ankle. 1, 151-158. 